\title{
TEORES DE METAIS PESADOS E CARACTERIZAÇÃO MINERALÓGICA DE SOLOS DO CEMITÉRIO MUNICIPAL DE SANTA CÂNDIDA, CURITIBA (PR) ${ }^{(1)}$
}

\author{
Yara Jurema Barros ${ }^{(2)}$, Vander de Freitas Melo ${ }^{(3)}$, Sônia Zanello(4), \\ Elma Neri de Lima Romanó ${ }^{(5)}$ \& Patrícia Rafaela Luciano ${ }^{(2)}$
}

\begin{abstract}
RESUMO
As partes metálicas dos caixões, como alças e adereços, são consideradas as principais fontes de contaminação dos solos de cemitério por metais pesados. Outras fontes de poluentes são os produtos usados no embalsamento de corpos, conservantes da madeira de caixões e líquidos humurosos liberados na decomposição. Os objetivos deste trabalho foram estudar a mineralogia da fração de argila e os teores de metais pesados de solos do Cemitério Municipal de Santa Cândida, Curitiba (PR), e estimar o risco de contaminação ambiental por esses poluentes. Foram selecionados sete locais, de onde se coletaram amostras em três profundidades $(0-20,20-80$ e $80-120 \mathrm{~cm})$, representando dois materiais de origem (granito/gnaisse e argilito) e dois tipos de sepultura (de indigentes e por jazigos). A fração de argila foi estudada por difratometria de raios $\mathrm{X}$ e análises térmicas. Determinaram-se os teores de $\mathrm{Fe}$ e $\mathrm{Al}$ nos extratos das amostras com oxalato de amônio ácido (óxidos de Fe e Al de baixa cristalinidade) e com ditionito-citratobicarbonato (óxidos de Fe cristalinos) por espectrometria de absorção atômica (EAA). Os teores totais e trocáveis de $\mathrm{Cr}, \mathrm{Cu}, \mathrm{Pb}, \mathrm{Ni}$ e $\mathrm{Zn}$ foram determinados por EAA, após digestão das amostras com $\mathrm{HF}$ concentrado e solução de $\mathrm{BaCl}_{2} 1 \mathrm{~mol} \mathrm{~L}^{-1}$, respectivamente. A ocorrência de vermiculita hidroxi-Al entrecamadas e esmectita, além do predomínio de caulinita na fração de argila, determinou os altos valores de capacidade de troca catiônica (CTC) dos solos. Na área de jazigos, as amostras de solos apresentaram os maiores teores de metais pesados, com valores máximos de $\mathrm{Cr}$ e $\mathrm{Pb}$, na ordem de 516,3 e 260,2 $\mathrm{mg} \mathrm{kg}^{-1}$, respectivamente. A menor
\end{abstract}

\footnotetext{
(1) Recebido para publicação em março de 2007 e aprovado em maio de 2008.

(2) Mestranda do Programa de Pós-Graduação em Ciência do Solo, Departamento de Solos e Engenharia Agrícola, Universidade Federal do Paraná - UFPR. Rua dos Funcionários 1540, CEP 80035-050 Curitiba (PR). E-mail: yarajuba@gmail.com

${ }^{(3)}$ Professor do Departamento de Solos e Engenharia Agrícola, UFPR. Bolsista do CNPq. E-mail: vanderfm@ufpr.br

(4) Professora do Departamento de Química e Biologia, Universidade Tecnológica Federal do Paraná - UTFPR. Av. 7 de Setembro 3165, Rebouças, CEP 80230-010 Curitiba (PR). E-mail: zanello@utfpr.edu.br

(5) Funcionária do IAP a disposição do Departamento de Solos e Engenharia Agrícola, UFPR. E-mail: elmanery@gmail.com
} 
contaminação na área de indigentes pode ser atribuída à maior simplicidade dos sepultamentos, com menor quantidade de fontes potenciais de metais pesados, como conservantes da madeira e as partes metálicas dos caixões. As características químicas e mineralógicas do solo, em parte determinadas pelo material de origem, não apresentaram relação de causa e efeito com metais pesados nas áreas estudadas.

Termos de indexação: caulinita, argilominerais 2:1, capacidade de troca catiônica, contaminação do solo.

\title{
SUMMARY: HEAVY METAL CONTENTS AND MINERALOGICAL CHARACTERIZATION OF SOILS FROM THE SANTA CÂNDIDA MUNICIPAL CEMETERY, IN CURITIBA (PR, BRAZIL)
}

\begin{abstract}
The metal pieces of coffins, such as handles and adornments, are considered the main source of soil heavy metal contamination. Other sources of pollutants are the products used in the body embalming, wood preservatives and fluids released from body decomposition. The purpose of this study was to investigate the clay fraction mineralogy and heavy metal contents of soils from Santa Cândida Municipal Cemetery, in Curitiba $(P R)$, and estimate the contamination risk. The samples were collected at three depths $(0$ $20,20-80$ and $80-120 \mathrm{~cm})$ at seven selected points, representing two parent materials (granite/gneiss and claystone) and two burial modalities (unmarked graves and mausoleum area). The clay fraction was studied by $X$ ray diffractometry and thermal analysis, and $F e$ and $\mathrm{Al}$ contents were determined, after acid ammonium oxalate (amorphous $\mathrm{Fe}$ and $\mathrm{Al}$ oxides) and sodium citrate-bicarbonate-dithionite (crystalline Fe oxides) extractions, by atomic absorption spectroscopy (AAS). The total and exchangeable heavy metal contents were determined by $A A S$, after sample digestion with concentrated $\mathrm{HF}$ and $\mathrm{BaCl}_{2} 1 \mathrm{~mol} \mathrm{~L}$ ${ }^{1}$ solution, respectively. The predominance of kaolinite and occurrence of vermiculite with Al-hydroxy interlayers and smectite determined the high values of soil CEC. Heavy metal contents were higher in the mausoleum area, where the highest $\mathrm{Cr}$ and $\mathrm{Pb}$ contents were found (516.3 and $260.2 \mathrm{mg} \mathrm{kg}^{-1}$, respectively). The lower metal contamination in the area of unmarked graves may be attributed to simpler burial practices, with less potential heavy metal sources, such as wood preservatives and metal parts of coffins. No causeeffect relation was observed between the chemical and mineralogical soil characteristics, in part determined by the parent material, and the heavy metal contents in the studied area.
\end{abstract}

Index terms: kaolinite, 2:1 clay minerals, cation exchange capacity, soil contamination.

\section{INTRODUÇÃO}

A palavra cemitério, do grego Koumetèrian (de Kcmão), designava, a princípio, o lugar onde se dorme (quarto ou dormitório). Foi sobre a influência do Cristianismo que o termo tomou o sentido de campo de descanso após a morte. O termo só pode ser corretamente utilizado para locais em que se sepultam corpos por inumação, ou seja, enterramento direto no solo. A partir da Idade Média, começou-se a falar em cemitérios, quando se enterravam os mortos nas igrejas ou em suas imediações (Pacheco, 1986).

Os caixões construídos de madeira não se apresentam como a principal fonte de contaminação do solo, a menos que conservantes da madeira fontes de metais pesados, principalmente $\mathrm{Cr}$, ou à base de organoclorados, como o pentaclorofenol, estejam presentes. Entretanto, madeiras não tratadas se decompõem rapidamente, permitindo uma rápida disseminação de líquidos humurosos. Caixões de metal, normalmente não utilizados em sepultamentos, podem causar contaminação do solo por $\mathrm{Fe}, \mathrm{Cu}, \mathrm{Pb}$ e Zn durante vários anos, especialmente em solos com baixo pH (Spongberg \& Becks, 2000).

Contaminantes químicos, como As e $\mathrm{Hg}$, usados em práticas de embalsamento de corpos com formaldeído, podem ter sido responsáveis, no passado, pela contaminação do solo e da água em cemitérios. Atualmente, constituem-se em fontes de contaminantes químicos o verniz e conservantes da madeira e as partes metálicas dos caixões, como alças e adereços, que podem liberar $\mathrm{Pb}, \mathrm{Zn}, \mathrm{Cu}$, Cr e Ni e Fe (Spongberg 
$\&$ Becks, 2000). Os resultados obtidos por esses autores em cemitério de Ohio, USA, mostraram que os metais no solo estavam associados com os caixões de corpos sepultados desde o século XVIII. Os solos apresentavam maiores teores de $\mathrm{Fe}, \mathrm{Pb}, \mathrm{Cu}, \mathrm{Zn}, \mathrm{Co}$ e As na profundidade dos sepultamentos.

A grande maioria dos estudos sobre contaminação do solo por cemitérios tem-se concentrado em poluentes não-metálicos. Segundo Pacheco (1997), nos líquidos humurosos, ocorrem duas diaminas muito tóxicas, que são a putrescina (1,4 butanodiamina) e a cadaverina (1,5 pentanodiamina). Existem registros de alguns casos de contaminação das águas subterrâneas por líquidos humurosos, oriundos de cadáveres, em águas que se destinavam ao consumo humano (Bouwer, 1978). De acordo com esse autor, a construção de cemitérios não deve ser em solos com alta permeabilidade ou solos com textura tão fina que prevaleçam as condições de anaerobiose. Solos com textura média, com o nível hidrostático a pelo menos 2,5 m da superfície, deixando uma zona insaturada (distância do caixão em nível hidrostático) de pelo menos $0,7 \mathrm{~m}$, devem ser preferidos para evitar a contaminação da água subterrânea. Pacheco (1997) concluiu que amostras de águas subterrâneas de três cemitérios do Brasil, com diferentes tipos de solos, estavam insatisfatórias sob o ponto de vista sanitário. Coliformes fecais, bactérias proteolíticas e lipolíticas foram abundantes em algumas amostras de água. As menores contaminações ocorreram em solos mais argilosos.

A escolha do local para a construção de cemitério deve ser feita com critério, observando as características do meio físico, como relevo e hidrologia, e atributos do solo, como profundidade efetiva, textura, densidade aparente, teor de matéria orgânica, mineralogia da fração de argila, entre outros.

Em camadas mais profundas do solo, onde normalmente ocorrem os sepultamentos (1,5 a 1,8 m), o teor e a qualidade da argila são fatores importantes para definir a capacidade de adsorção de metais pesados. Em solos tropicais e subtropicais úmidos, a mineralogia constitui-se principalmente de caulinita, óxidos de Fe (hematita e goethita), óxidos de Al (gibbsita) e, em menores proporções, minerais do tipo 2:1 (esmectita e vermiculita) (Curi \& Franzmeier, 1984; Singh \& Gilkes, 1992; Melo et al., 2001a,b). Os componentes coloidais do solo (minerais da fração argila e fração húmica) apresentam alta capacidade de troca de cátions (CTC), que, em grande parte, determina a capacidade de armazenamento de íons e o poder-tampão do solo para poluentes, como os metais pesados (Sposito, 1984; Elliott et al., 1986; Naidu et al., 1998).

Atualmente, Curitiba possui 24 cemitérios, situados em locais onde não foram efetuados estudos do meio físico (Romanó, 2003). A avaliação da contaminação dos solos dos cemitérios por metais pesados é muito limitada, principalmente por entraves burocráticos ao acesso à área (autorização das autoridades públicas) e de coleta das amostras em meio às sepulturas.

Os objetivos deste trabalho foram estudar a mineralogia da fração de argila e os teores de metais pesados dos solos do Cemitério Municipal de Santa Cândida, Curitiba (PR), e estimar o risco de contaminação ambiental por esses poluentes.

\section{MATERIAL E MÉTODOS}

\section{Descrição da área e dos procedimentos de coleta das amostras}

O Cemitério Municipal de Santa Cândida encontrase localizado no bairro de Santa Cândida em Curitiba, meridiano central - $51^{\circ}$, entre as coordenadas UTM 678.000 e $679.000 \mathrm{~m}$ este e 7.192 .000 e 7.193.000 m norte. A escolha deste cemitério para o estudo foi em razão das características de relevo e hidrologia da área, com túmulos localizados em áreas mais altas, com o nível hidrostático mais distante da superfície do solo, e outros próximos aos cursos de água. O relevo da área do cemitério apresenta declividade acentuada, acima de $10 \%$ em mais da metade da área, e o regolito do local possui profundidade em torno de 1,20 m, sendo a profundidade do nível hidrostático na área mais baixa do terreno de apenas 0,9 a $1,4 \mathrm{~m}$ (Romanó, 2003). É oportuno ressaltar que o estudo teve a autorização do Ministério Público do Estado do Paraná e da Promotoria de Meio Ambiente do Estado do Paraná.

Segundo o mapa geológico do local (Romanó, 2003), as rochas de origem dos solos pertencem à Formação Guabirotuba, constituindo-se principalmente de argilitos e arenitos, e ao Complexo Cristalino (granito/ gnaisse) (Quadro 1). A Formação Guabirotuba provém do Período Quaternário, formado por depósitos fluviais e lacustres (Bigarella \& Salamuni, 1962). Essa formação consiste de material formado por depósitos pouco consolidados, constituídos de argilitos e arenitos (Salamuni \& Stellfeld, 2001). Nos solos sob domínio da Formação Guabirotuba, prevalece a textura argilosa, com argilas expansivas, mas com contribuições das frações sílticas e arenosas (Archela, 1986).

De acordo com Embrapa (1984), a maior parte da área da região metropolitana de Curitiba, cerca de 87,5 \%, é constituída por Cambissolo (60 \%), Latossolo (17\%) e solos orgânicos (10,5\%). Na área onde o cemitério foi implantado predominavam os Cambissolos. Na situação atual, os solos foram classificados como Antropossolos, segundo Curcio et al. (2004), pois não apresentam as características originais, principalmente dos horizontes superficiais, que se descaracterizaram devido à introdução de material antropogênico. 
Para a amostragem dos solos, procurou-se representar a extensão do cemitério, distribuindo os locais de coleta de solo em diferentes pontos da área. Outros critérios considerados na amostragem foram: gradiente de profundidade do nível hidrostático; duas modalidades de sepulturas (jazigos e indigentes Quadro 1) e duas litologias do terreno (argilito e granito/gnaisse - Quadro 1). $\mathrm{Na}$ área de jazigos (Pontos de 1 a 5), as coletas foram realizadas nos corredores e, na área de indigentes (Pontos 6 e 7), a amostragem foi realizada de forma aleatória, uma vez que não havia definição de corredores, com a possibilidade de coletar sobre sepulturas e ter na amostra partes de caixões (Figura 1c), ossos, tecidos, etc.

Para cada ponto de amostragem, foi aberta uma trincheira de $60 \times 100 \mathrm{~cm}$ de largura e $120 \mathrm{~cm}$ de profundidade. A coleta de amostras simples de solo foi efetuada nas profundidades de 0 a 20,20 a 80 e 80 a $120 \mathrm{~cm}$, com auxílio de faca e pá de corte reta. As amostras de solo foram encaminhadas ao Laboratório de Mineralogia do Solo da Universidade Federal do Paraná, onde foram secas ao ar e passadas por peneiras de $2 \mathrm{~mm}$ de malha, tornando-se amostras de terra fina seca ao ar (TFSA). A caracterização química de rotina e a análise granulométrica dos solos foram realizadas segundo método descrito por Embrapa (1979) (Quadro 1).

\section{Análise mineralógica da fração de argila}

Para a separação das frações do solo, amostras da TFSA foram tratadas com peróxido de hidrogênio 30 volumes, para remoção de matéria orgânica, e com $\mathrm{NaOH} 0,2 \mathrm{~mol} \mathrm{~L}^{-1}$, para dispersão das partículas (Jackson, 1979). Após esses tratamentos prévios, a fração de areia foi retida em peneira de $0,05 \mathrm{~mm}$, e as frações argila e silte foram recolhidas em provetas de $1.000 \mathrm{~mL}$ e separadas por sedimentação com base na lei de Stokes (Gee \& Bauder, 1986).

Amostras da fração de argila foram moídas em almofariz e montadas em placas perfuradas (amostras não orientadas) para a identificação dos minerais por difratometria de raios X (DRX). Os difratogramas foram obtidos em goniômetro vertical Philips, modelo PW1050/70, com velocidade de $1^{\circ} 2 \theta \mathrm{min}^{-1}$ e amplitude de 4 a $65^{\circ} 2 \theta$. O difratômetro, equipado com filtro de $\mathrm{Ni}$ e utilizando radiação $\mathrm{CuK} \alpha$, foi operado a $20 \mathrm{~mA}$ e $40 \mathrm{kV}$. Foram realizados tratamentos adicionais para diferenciar os minerais secundários do tipo 2:1 da fração de argila (Whittig \& Allardice, 1986): saturação com Mg, saturação com Mg e solvatação com glicerol e saturação com Ke secagem ao ar. Após os tratamentos, as amostras foram montadas em lâminas de vidro, utilizando-se a técnica do esfregaço (amostras orientadas), e analisadas por DRX, numa amplitude de 3 a $15^{\circ} 2 \theta$. Aproveitou-se a amostra saturada com

Quadro 1. Análises químicas e granulométrica das amostras dos solos do Cemitério Municipal de Santa Cândida $^{(1)}$

\begin{tabular}{|c|c|c|c|c|c|c|c|c|c|c|c|c|c|c|}
\hline $\begin{array}{c}\text { Ponto de } \\
\text { amostragem }\end{array}$ & Litologia & $\begin{array}{c}\text { Tipo de } \\
\text { sepultamento }\end{array}$ & $\begin{array}{c}\text { Profundidade } \\
\text { de coleta }\end{array}$ & $\begin{array}{c}\mathrm{pH} \\
\mathrm{CaCl}_{2}\end{array}$ & $\mathrm{Al}^{3+}$ & $\mathbf{H}+\mathbf{A l}$ & $\mathrm{Mg}^{2+}$ & $\mathrm{Ca}^{2+}$ & $\mathbf{K}^{+}$ & $\begin{array}{l}\text { CTC } \\
\text { total }\end{array}$ & $\mathrm{CO}$ & V & $\mathbf{T}^{(2)}$ & Argila \\
\hline \multirow[b]{2}{*}{$\mathrm{P} 1$} & \multirow[b]{2}{*}{ Argilito } & \multirow[b]{2}{*}{ Jazigo } & $\mathrm{cm}$ & & \multicolumn{6}{|c|}{$-\mathrm{cmol}_{\mathrm{c}} \mathrm{dm}^{-3}$} & $\mathrm{~g} \mathrm{dm}^{-3}$ & $\%$ & $\mathrm{cmol}_{\mathrm{c}} \mathrm{dm}^{-3}$ & $\mathrm{~g} \mathrm{~kg}^{-1}$ \\
\hline & & & $\begin{array}{c}0-20 \\
20-80 \\
80-120\end{array}$ & $\begin{array}{l}4,0 \\
4,0 \\
3,9\end{array}$ & $\begin{array}{l}4,0 \\
4,0 \\
3,9\end{array}$ & $\begin{array}{l}20,4 \\
22,0 \\
22,0\end{array}$ & $\begin{array}{l}1,1 \\
1,1 \\
2,4\end{array}$ & $\begin{array}{l}0,9 \\
1,0 \\
1,1\end{array}$ & $\begin{array}{l}0,2 \\
1,2 \\
0,2\end{array}$ & $\begin{array}{l}22,6 \\
24,3 \\
25,7\end{array}$ & $\begin{array}{l}7,5 \\
4,5 \\
1,5\end{array}$ & $\begin{array}{r}9,8 \\
9,4 \\
14,2\end{array}$ & $\begin{array}{l}43,0 \\
50,7 \\
50,5\end{array}$ & $\begin{array}{l}526 \\
479 \\
449\end{array}$ \\
\hline $\mathrm{P} 2$ & Argilito & Jazigo & $\begin{array}{c}0-20 \\
20-80 \\
80-120\end{array}$ & $\begin{array}{l}4,8 \\
5,5 \\
5,7\end{array}$ & $\begin{array}{l}4,8 \\
5,5 \\
5,7\end{array}$ & $\begin{array}{l}6,2 \\
5,0 \\
3,7\end{array}$ & $\begin{array}{l}2,5 \\
2,8 \\
2,6\end{array}$ & $\begin{array}{l}4,1 \\
6,6 \\
4,4\end{array}$ & $\begin{array}{l}0,2 \\
0,1 \\
0,1\end{array}$ & $\begin{array}{l}13,0 \\
14,5 \\
10,8\end{array}$ & $\begin{array}{r}13,6 \\
15,4 \\
7,5\end{array}$ & $\begin{array}{l}52,2 \\
65,5 \\
65,7\end{array}$ & $\begin{array}{l}26,5 \\
28,3 \\
19,8\end{array}$ & $\begin{array}{l}488 \\
511 \\
545\end{array}$ \\
\hline P3 & Argilito & Jazigo & $\begin{array}{c}0-20 \\
20-80 \\
80-120\end{array}$ & $\begin{array}{l}4,8 \\
4,1 \\
4,1\end{array}$ & $\begin{array}{l}4,8 \\
4,1 \\
4,1\end{array}$ & $\begin{array}{r}6,7 \\
11,3 \\
11,3\end{array}$ & $\begin{array}{l}2,5 \\
0,9 \\
0,8\end{array}$ & $\begin{array}{l}6,0 \\
1,2 \\
0,7\end{array}$ & $\begin{array}{l}0,2 \\
0,1 \\
0,1\end{array}$ & $\begin{array}{l}15,4 \\
13,5 \\
12,9\end{array}$ & $\begin{array}{r}28,7 \\
14,8 \\
4,5\end{array}$ & $\begin{array}{l}56,5 \\
16,2 \\
12,1\end{array}$ & $\begin{array}{l}34,6 \\
25,5 \\
24,1\end{array}$ & $\begin{array}{l}445 \\
529 \\
534\end{array}$ \\
\hline $\mathrm{P} 4$ & Argilito & Jazigo & $\begin{array}{c}0-20 \\
20-80 \\
80-120\end{array}$ & $\begin{array}{l}3,8 \\
3,9 \\
3,9\end{array}$ & $\begin{array}{l}3,8 \\
3,9 \\
3,9\end{array}$ & $\begin{array}{l}15,2 \\
15,2 \\
16,3\end{array}$ & $\begin{array}{l}0,8 \\
0,8 \\
0,5\end{array}$ & $\begin{array}{l}0,7 \\
0,7 \\
0,5\end{array}$ & $\begin{array}{l}0,1 \\
0,1 \\
0,1\end{array}$ & $\begin{array}{l}16,8 \\
16,8 \\
17,4\end{array}$ & $\begin{array}{r}31,7 \\
18,4 \\
5,1\end{array}$ & $\begin{array}{l}9,4 \\
9,4 \\
6,2\end{array}$ & $\begin{array}{l}38,4 \\
29,7 \\
32,9\end{array}$ & $\begin{array}{l}437 \\
564 \\
528\end{array}$ \\
\hline P5 & Granito/gnaisse & Jazigo & $\begin{array}{c}0-20 \\
20-80 \\
80-120\end{array}$ & $\begin{array}{l}5,3 \\
3,9 \\
3,9\end{array}$ & $\begin{array}{l}5,3 \\
3,9 \\
3,9\end{array}$ & $\begin{array}{r}4,6 \\
13,1 \\
16,3\end{array}$ & $\begin{array}{l}3,3 \\
1,0 \\
0,8\end{array}$ & $\begin{array}{l}7,0 \\
0,9 \\
0,8\end{array}$ & $\begin{array}{l}0,1 \\
0,1 \\
0,1\end{array}$ & $\begin{array}{l}16,0 \\
15,1 \\
18,0\end{array}$ & $\begin{array}{r}19,6 \\
17,2 \\
3,9\end{array}$ & $\begin{array}{r}71,2 \\
13,0 \\
9,2\end{array}$ & $\begin{array}{l}39,7 \\
39,7 \\
35,0\end{array}$ & $\begin{array}{l}402 \\
379 \\
513\end{array}$ \\
\hline $\mathrm{P} 6$ & Granito/gnaisse & Indigente & $\begin{array}{c}0-20 \\
20-80 \\
80-120\end{array}$ & $\begin{array}{l}3,9 \\
4,0 \\
4,2\end{array}$ & $\begin{array}{l}3,9 \\
4,0 \\
4,2\end{array}$ & $\begin{array}{r}15,2 \\
13,1 \\
8,4\end{array}$ & $\begin{array}{l}0,4 \\
0,6 \\
0,8\end{array}$ & $\begin{array}{l}0,5 \\
0,9 \\
1,2\end{array}$ & $\begin{array}{l}0,1 \\
0,1 \\
0,1\end{array}$ & $\begin{array}{l}16,2 \\
14,7 \\
10,5\end{array}$ & $\begin{array}{r}22,6 \\
12,4 \\
5,1\end{array}$ & $\begin{array}{r}6,1 \\
10,8 \\
19,9\end{array}$ & $\begin{array}{l}31,5 \\
27,8 \\
19,4\end{array}$ & $\begin{array}{l}514 \\
528 \\
541\end{array}$ \\
\hline $\mathrm{P} 7$ & Granito/gnaisse & Indigente & $\begin{array}{c}0-20 \\
20-80 \\
80-120\end{array}$ & $\begin{array}{l}3,9 \\
3,9 \\
4,0\end{array}$ & $\begin{array}{l}3,9 \\
3,9 \\
4,0\end{array}$ & $\begin{array}{l}14,1 \\
14,1 \\
12,1\end{array}$ & $\begin{array}{l}0,4 \\
0,3 \\
0,4\end{array}$ & $\begin{array}{l}0,6 \\
0,7 \\
0,5\end{array}$ & $\begin{array}{l}0,1 \\
0,0 \\
0,0\end{array}$ & $\begin{array}{l}15,2 \\
15,1 \\
13,0\end{array}$ & $\begin{array}{r}13,6 \\
9,4 \\
6,9\end{array}$ & $\begin{array}{l}7,0 \\
6,9 \\
7,2\end{array}$ & $\begin{array}{l}33,0 \\
26,0 \\
22,4\end{array}$ & $\begin{array}{l}459 \\
582 \\
582\end{array}$ \\
\hline
\end{tabular}

(1) Fonte: Romanó (2003). ${ }^{(2)} \mathrm{T}$ (atividade da fração de argila) = CTC total/teor de argila $\left(\mathrm{g} \mathrm{kg}{ }^{-1}\right) * 1.000$. 

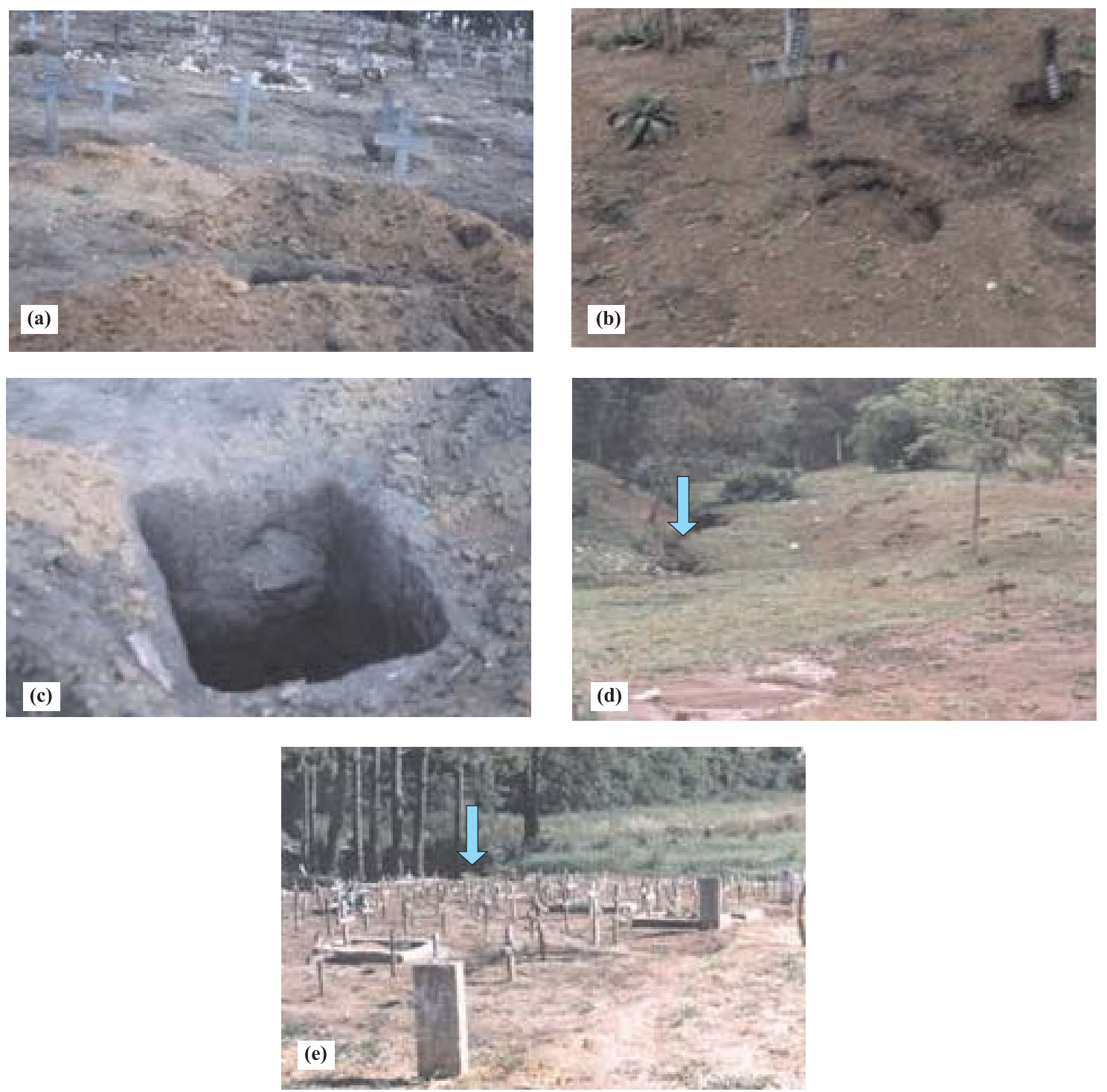

Figura 1. Pontos de amostragem em área onde indigentes foram sepultados (P6 e P7): (a) localização de uma trincheira; (b) detalhe do afundamento do terreno e escorrimento de necrochorume; (c) trincheira com presença de parte de caixão; (d) e (e) localização dos rios, indicada pela seta, em relação aos sepultamentos.

$\mathrm{K}$, e, após aquecimento a $550{ }^{\circ} \mathrm{C}$ em mufla, analisou-se novamente a lâmina por DRX nas mesmas condições.

Para determinar os teores e a composição química dos óxidos de $\mathrm{Fe}$ e $\mathrm{Al}$ de baixa cristalinidade e óxidos de Fe mais cristalinos, foram utilizadas extrações com oxalato de amônio 0,2 $\mathrm{mol} \mathrm{L}^{-1}, \mathrm{pH} \mathrm{3,0}$ (OA) (McKeague, 1978) e ditionito-citrato-bicarbonato (DCB) (Mehra \& Jackson, 1960), respectivamente, conforme detalhes apresentados por Melo et al. (2001b). Os teores de $\mathrm{Fe}$ e $\mathrm{Al}$ foram determinados por espectrometria de absorção atômica (EAA). Após a lavagem do resíduo da extração com OA com solução de $\left(\mathrm{NH}_{4}\right)_{2} \mathrm{CO}_{3} 1 \mathrm{~mol} \mathrm{~L}^{-1}$ e água deionizada para remover o excesso de sais, foi determinada a quantidade de material de baixa cristalinidade extraída pela diferença entre a massa seca ( $24 \mathrm{~h}$ em estufa a $105^{\circ} \mathrm{C}$ ) antes e após o tratamento.

As amostras da fração de argila, tratadas com DCB, foram analisadas em derivatógrafo SHIMADZU DTG-60. A interpretação qualitativa foi feita pelas características dos picos endotérmico e exotérmico dos minerais em análise termodiferencial e a quantificação da caulinita e gibbsita foi realizada de acordo com a magnitude de redução da massa da amostra, em decorrência da desidroxilação dos minerais (Jackson, 1979).

Determinação dos teores totais e trocáveis de metais pesados totais nas amostras de solos

A digestão das amostras de solo com ácidos concentrados $\left(\mathrm{HF}, \mathrm{HNO}_{3}, \mathrm{H}_{2} \mathrm{SO}_{4}\right.$ e $\left.\mathrm{HClO}_{4}\right)$ para 
obtenção de extrato foi realizada segundo o método de Lim \& Jackson (1986). Os teores totais de $\mathrm{Cr}, \mathrm{Cu}$, $\mathrm{Pb}, \mathrm{Ni}$ e $\mathrm{Zn}$ foram dosados por EAA. Para determinação dos teores trocáveis desses metais, $5 \mathrm{~g}$ de TFSA foram agitados por $2 \mathrm{~h}$ com $50 \mathrm{~mL}$ de solução extratora $\mathrm{BaCl}_{2}$ 0,1 mol L-1 (Jones et al., 1973). Então, a suspensão foi filtrada e a determinação dos metais foi feita conforme descrito anteriormente.

\section{Análise dos dados}

Os dados das análises granulométrica e químicas de rotina (Quadro 1) e caracterização mineralógica e teores de metais pesados foram submetidos à análise de correlação simples de Pearson, utilizando-se o programa SPSS for Windows 10.0. Os teores de metais pesados foram confrontados com os valores de referências de qualidade de solo estabelecidos pela CETESB (2001), e a estimativa do risco de contaminação ambiental foi com base nos teores totais e trocáveis de metais pesados, na distância dos perfis aos leitos de rios, nas características químicas e mineralógicas dos solos e na modalidade de sepultamento.

\section{RESULTADOS E DISCUSSÃO}

\section{Caracterização mineralógica da fração de argila}

Os óxidos de $\mathrm{Fe}$ e $\mathrm{Al}$ menos cristalinos extraídos com oxalato de amônio (OA) apresentam muitos sítios de adsorção de íons, por apresentarem maior superfície específica e número de cargas superficiais dependentes de $\mathrm{pH}$ (McKeaque \& Day, 1966) em relação aos óxidos cristalinos, como a hematita, goethita e gibbsita, o que confere aos solos, por exemplo, maior adsorção específica de metais pesados. Nas amostras analisadas, os teores desses óxidos foram baixos (Quadro 2), sendo o material dissolvido pelo OA constituído principalmente por $\mathrm{Al}$.

Para um mesmo ponto de coleta, não foram verificados maiores teores de material de baixa cristalinidade na camada superficial de $0-20 \mathrm{~cm}$ (Quadro 2), onde se esperava maior remoção pelo OA devido aos maiores teores de C orgânico (Quadro 1). Vários autores demonstraram a relação direta entre óxidos de $\mathrm{Fe}$ e $\mathrm{Al}$ de baixa cristalinidade e teores de

Quadro 2. Teores de óxidos de ferro e alumínio extraídos pelo oxalato de amônio (OA) e ditionito-citratobicarbonato (DCB) da fração de argila das amostras dos solos do Cemitério Municipal de Santa Cândida ${ }^{(1)}$

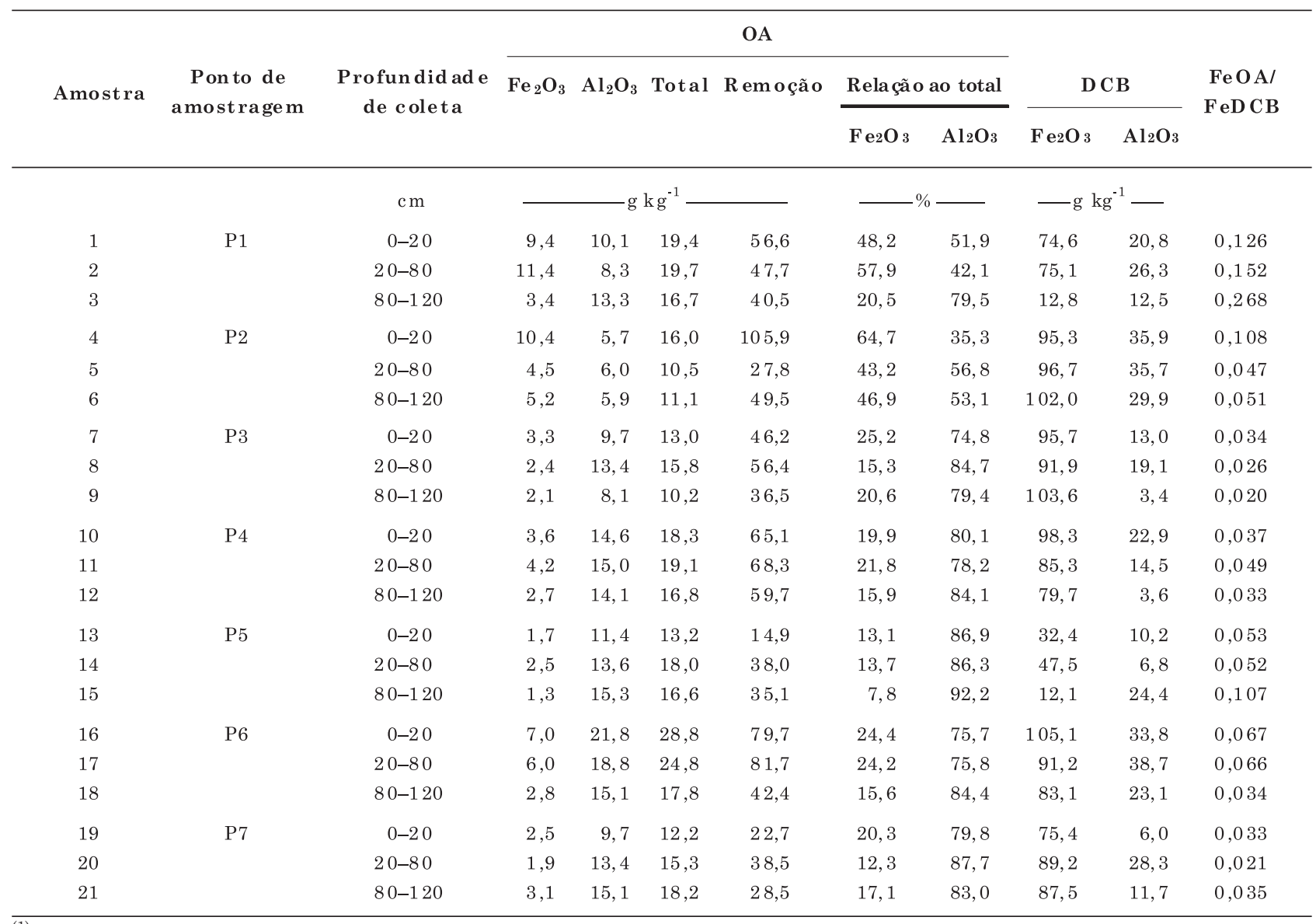

(1) Remoção = redução em massa da amostra: (peso inicial - peso final) x 1.000 / peso inicial. Relação ao total - participação de $\mathrm{Fe}_{2} \mathrm{O}_{3}$ e $\mathrm{Al}_{2} \mathrm{O}_{3}$ em relação ao total (soma dos óxidos). Relação $\mathrm{FeOA} / \mathrm{FeDCB}$ - Relação entre os teores de $\mathrm{Fe}_{2} \mathrm{O}_{3} \mathrm{OA}$ e $\mathrm{Fe}{ }_{2} \mathrm{O}_{3} \mathrm{DCB}_{\text {. }}$ 
C orgânico (Melo et al., 2001b; Ghidin et al., 2006), pois a fração húmica tem efeito inibidor na cristalização desses minerais (Kämpf \& Schwertmann, 1983). Apesar dos freqüentes revolvimentos do solo no cemitério, os teores de $\mathrm{C}$ orgânico total mantiveramse superiores na superfície (Quadro 1). Possivelmente, outros fatores relacionados à atividade antrópica, como a decomposição de cadáveres, estão determinando maior concentração de material de baixa cristalinidade nas camadas subsuperficiais (Quadro 2). Devido a esse comportamento atípico, os coeficientes de correlação entre o teor de óxidos de $\mathrm{Fe}$ e $\mathrm{Al}$ determinados por $\mathrm{OA}$ e o teor de $\mathrm{C}$ orgânico total foram baixos e não-significativos. Outro fator que favorece o enriquecimento de minerais de baixa cristalinidade é a presença do nível hidrostático próximo à superfície do solo (Wowk \& Melo, 2005; Zanello, 2006). Neste estudo, as amostras do Ponto 5 (localizado nas cotas mais baixas do terreno) não apresentaram maiores teores de $\mathrm{Fe}$ e $\mathrm{Al}$ determinados por $\mathrm{OA}$, em relação aos demais pontos de amostragem (Quadro 2). Mesmo com a proximidade do leito do rio, não se observaram evidências de hidromorfismo nesse ponto de coleta.

Os teores de $\mathrm{Fe}_{2} \mathrm{O}_{3}$ associados com minerais de $\mathrm{Fe}$ mais cristalinos extraídos com ditionito-citratobicarbonato (DCB) foram baixos e variaram de 12,8 a $103,6 \mathrm{~g} \mathrm{~kg}^{-1}$ (Quadro 2), o que reflete os baixos teores de Fe dos materiais de origem dos solos (argilito da Formação Guabirotuba e granito/gnaisse) e diferentes estádios de desenvolvimento dos solos. Não houve distinção nos teores de $\mathrm{Fe}_{2} \mathrm{O}_{3}$-DCB entre os solos originados de granito/gnaisse (Pontos de 1 a 4 Quadro 1) e de argilito (Pontos de 5 a 7). A goethita e a hematita são as principais fontes de Fe extraído pelo DCB na fração de argila. A quantidade de $\mathrm{Al}$ extraída pelo DCB (Quadro 2) é diretamente proporcional ao nível de substituição isomórfica de $\mathrm{Fe}$ por $\mathrm{Al}$ na estrutura desses minerais (Curi \& Franzmeier, 1984). Mesmo não sendo quantificados, detectou-se a presença de hematita e goethita em quase todas as amostras por DRX (Quadro 3). Os menores teores de $\mathrm{Fe}_{2} \mathrm{O}_{3}$ DCB no Ponto 5, em decorrência da maior proximidade do rio, são coerentes com a ausência de hematita nas amostras coletadas em maiores profundidades. Os principais fatores que favorecem a formação de hematita em detrimento da goethita no solo são maiores teores de $\mathrm{Fe}$ no material de origem, altas temperaturas, menor grau de umidade e teor de matéria orgânica e valores de $\mathrm{pH}$ mais altos (Kämpf \& Schwertmann, 1983; Schwertmann \& Kämpf, 1985; Schwertmann \& Taylor, 1989).

A caulinita foi o principal mineral da fração argila dos solos, onde seus teores variaram de 481 a $748 \mathrm{~g} \mathrm{~kg}^{-1}$ (Quadro 3). Assim, mesmo apresentando

Quadro 3. Mineralogia da fração de argila das amostras dos solos do Cemitério Municipal de Santa Cândida ${ }^{(1)}$

$\begin{array}{ccc}\text { Amostra } & \begin{array}{c}\text { Ponto de } \\ \text { amostragem }\end{array} & \begin{array}{c}\text { Profundidade } \\ \text { de coleta }\end{array}\end{array}$ Caulinita Gibbsita $\begin{gathered}\text { Material } \\ \text { amorfo }\end{gathered}$ Total Goethita Hematita VHE Esmectita

\begin{tabular}{|c|c|c|c|c|c|c|c|c|c|c|}
\hline & & $\mathrm{cm}$ & 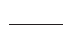 & $-\xi$ & 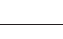 & - & & & & \\
\hline 1 & \multirow[t]{3}{*}{$\mathrm{P} 1$} & $0-20$ & 605 & 75 & 57 & 736 & $\mathrm{nq}$ & $\mathrm{nq}$ & $*$ & $\mathrm{nq}$ \\
\hline 2 & & $20-80$ & 559 & 60 & 48 & 666 & $\mathrm{nq}$ & $\mathrm{nq}$ & $*$ & $\mathrm{nq}$ \\
\hline 3 & & $80-120$ & 560 & 58 & 41 & 658 & $\mathrm{nq}$ & $\mathrm{nq}$ & $*$ & $\mathrm{nq}$ \\
\hline 4 & \multirow[t]{3}{*}{$\mathrm{P} 2$} & $0-20$ & 538 & 89 & 106 & 733 & $\mathrm{nq}$ & $\mathrm{nq}$ & $\mathrm{nq}$ & * \\
\hline 5 & & $20-80$ & 591 & 84 & 28 & 703 & $\mathrm{nq}$ & $\mathrm{nq}$ & $\mathrm{nq}$ & $*$ \\
\hline 6 & & $80-120$ & 635 & 98 & 50 & 782 & $\mathrm{nq}$ & $\mathrm{nq}$ & $\mathrm{nq}$ & $*$ \\
\hline 7 & \multirow[t]{3}{*}{ P3 } & $0-20$ & 595 & 90 & 46 & 730 & $\mathrm{nq}$ & $\mathrm{nq}$ & $\mathrm{nq}$ & * \\
\hline 8 & & $20-80$ & 635 & 65 & 56 & 756 & $\mathrm{nq}$ & $\mathrm{nq}$ & $\mathrm{nq}$ & * \\
\hline 9 & & $80-120$ & 667 & 76 & 37 & 780 & $\mathrm{nq}$ & $\mathrm{nq}$ & $\mathrm{nq}$ & $*$ \\
\hline 10 & \multirow[t]{3}{*}{$\mathrm{P} 4$} & $0-20$ & 476 & 69 & 65 & 611 & $\mathrm{nq}$ & $\mathrm{nq}$ & $\mathrm{nq}$ & $*$ \\
\hline 11 & & $20-80$ & 481 & 94 & 68 & 643 & $\mathrm{nq}$ & $\mathrm{nq}$ & $\mathrm{nq}$ & $*$ \\
\hline 12 & & $80-120$ & 609 & 63 & 60 & 732 & $\mathrm{nq}$ & $\mathrm{nq}$ & $\mathrm{nq}$ & $*$ \\
\hline 13 & \multirow[t]{3}{*}{$\mathrm{P} 5$} & $0-20$ & 748 & 55 & 15 & 818 & $\mathrm{nq}$ & $\mathrm{nq}$ & $\mathrm{nq}$ & $*$ \\
\hline 14 & & $20-80$ & 705 & 46 & 38 & 789 & $\mathrm{nq}$ & $*$ & $\mathrm{nq}$ & $*$ \\
\hline 15 & & $80-120$ & 612 & 27 & 35 & 675 & $\mathrm{nq}$ & $*$ & $\mathrm{nq}$ & $*$ \\
\hline 16 & \multirow[t]{3}{*}{$\mathrm{P} 6$} & $0-20$ & 613 & 95 & 80 & 788 & $\mathrm{nq}$ & $\mathrm{nq}$ & $\mathrm{nq}$ & * \\
\hline 17 & & $20-80$ & 602 & 101 & 82 & 785 & $\mathrm{nq}$ & $\mathrm{nq}$ & $\mathrm{nq}$ & $*$ \\
\hline 18 & & $80-120$ & 681 & 85 & 42 & 808 & $\mathrm{nq}$ & $\mathrm{nq}$ & $\mathrm{nq}$ & $*$ \\
\hline 19 & \multirow[t]{3}{*}{$\mathrm{P} 7$} & $0-20$ & 594 & 87 & 23 & 704 & $\mathrm{nq}$ & $\mathrm{nq}$ & $\mathrm{nq}$ & $*$ \\
\hline 20 & & $20-80$ & 655 & 115 & 39 & 809 & $\mathrm{nq}$ & $\mathrm{nq}$ & $\mathrm{nq}$ & $*$ \\
\hline 21 & & $80-120$ & 629 & 98 & 29 & 755 & $\mathrm{nq}$ & $\mathrm{nq}$ & $\mathrm{nq}$ & $*$ \\
\hline
\end{tabular}

(1) Caulinita e gibbsita determinadas com base na perda de massa da amostra de argila por meio de análise termogravimétrica (Jackson, 1979); Material amorfo, determinado pela redução em peso da amostra pelo tratamento com oxalato de amônio (Redução em massa da amostra = (peso inicial - peso final) x 1.000/peso inicial); VHE, vermiculita hidroxi-Al entre camadas; nq: mineral apenas identificado por DRX (análise qualitativa); *: mineral ausente por DRX. 
baixa CTC (McBride, 1994), processos físico-químicos importantes nos solos, como as reações de adsorção, formação e estabilização dos agregados, dinâmica de água no perfil, são fortemente influenciados por este argilomineral. De acordo com Sposito (1989), o ponto de carga zero (PCZ) da caulinita em solos está em torno de $4,0\left(\mathrm{pH} \mathrm{em} \mathrm{H}_{2} \mathrm{O}\right)$; para a sílica e para o grupo silanol, presente na borda do mineral, o PCZ é ainda menor ( $\mathrm{pH}_{\mathrm{PCZ}}$ em torno de 2) (Tarì et al.,1999). Como o $\mathrm{pH}$ em $\mathrm{CaCl}_{2} 1 \mathrm{~mol} \mathrm{~L}^{-1}$ das amostras foi superior a 3,8 (Quadro 1), espera-se o predomínio de cargas negativas nas bordas caulinita, favorecendo a adsorção de metais. Como verificado para os teores de $\mathrm{Fe}_{2} \mathrm{O}_{3}$ $\mathrm{DCB}$, não houve variações nos teores de caulinita em função do material de origem dos solos (Quadro 3).

A ocorrência de vermiculita hidroxi-Al entrecamadas (VHE), identificada em praticamente todas as amostras por DRX (Quadro 3), é importante, pois o mineral possui grande capacidade de adsorção, devido à sua alta superfície específica e CTC (Sparks, 1995). Os valores de CTC total das amostras foram altos e variaram de 13 a $25,7 \mathrm{cmol}_{\mathrm{c}} \mathrm{kg}^{-1}$ (Quadro 1). Com os tratamentos (saturação com $\mathrm{Mg}$, saturação com $\mathrm{Mg}$ e solvatação com glicerol, saturação com K e posterior aquecimento - Whittig \& Allardice, 1986) realizados na fração de argila, verificou-se também a ocorrência de esmectita, mineral com alta expansividade, no Ponto 1 (Quadro 3), o que resultou no maior valor de atividade da fração de argila das amostras coletadas nesse local (Quadro 1). Além da ocorrência generalizada dos minerais do tipo 2:1, independentemente do material de origem dos solos (argilito e granito/gnaisse), as intensidades das reflexões basais desses minerais por DRX foram similares entre as amostras da fração argila. De acordo com Archela (1996) e Pires et al. (2007a), é comum a ocorrência de argilas 2:1 em solos sob domínio da Formação Guabirotuba.

\section{Metais pesados nas amostras de solos}

Os teores naturais de metais pesados nos solos são fortemente influenciados pelo material de origem (Davis, 1990; Ker et al., 1993). Em Latossolos originados de diferentes rochas, Ker et al. (1993) obtiveram teores de $\mathrm{Pb}$ entre $24 \mathrm{e} 184 \mathrm{mg} \mathrm{kg}^{-1}$. Melo (1998) observou que os maiores teores totais de $\mathrm{Cr}$ (máximo de 115,1 $\mathrm{mg} \mathrm{kg}^{-1}$ ) estavam associados a solos originados de rochas básicas. Neste estudo, não houve variações consistentes nos teores de metais pesados em função do material de origem dos solos (Quadro 4).

Os teores totais de $\mathrm{Pb}$ e $\mathrm{Zn}$ oscilaram entre os limites de 17,1 e $260,2 \mathrm{mg} \mathrm{kg}^{-1}$ e de 73,9 e $136,0 \mathrm{mg} \mathrm{kg}^{-1}$, respectivamente (Quadro 4). Pires et al. (2007b), trabalhando com diferentes classes de solos originados de argilito da Formação Guabirotuba, na Região Metropolitana de Curitiba, encontraram teores totais de $\mathrm{Pb}$ e $\mathrm{Zn}$, sob condições naturais, muito inferiores $\left(\mathrm{Pb}-0,6\right.$ a $2,1 \mathrm{mg} \mathrm{kg}{ }^{-1}$ e $\mathrm{Zn}-4,1$ a $6,6 \mathrm{mg} \mathrm{kg}^{-1}$ ), o que poderia indicar contaminação por esses metais nos solos do cemitério. Segundo
Cholopecka et al. (1996), metais provenientes de diferentes fontes antrópicas são relativamente mais móveis e potencialmente mais fitodisponíveis que aqueles presentes no material de origem dos solos. $\mathrm{O}$ incremento de metais pesados nos solos de cemitérios está relacionado aos materiais usados na confecção de caixões, tintas e alças, processos de embalsamento e, ainda, dos próprios corpos em decomposição (Spongberg \& Becks, 2000).

Contudo, ao comparar os teores totais de $\mathrm{Pb}$, com exceção da amostra 6, e de Zn (Quadro 4) com os referenciais estabelecidos pela CETESB (2001), esses valores ficaram abaixo dos teores de alerta $(\mathrm{Pb}-$ $100 \mathrm{mg} \mathrm{kg}^{-1}$ e $\mathrm{Zn}-300 \mathrm{mg} \mathrm{kg}^{-1}$ ). Tais teores representam o limite máximo de metais pesados no solo para a área ser considerada não contaminada. De maneira geral, os teores totais de Cu também estão dentro dos limites de qualidade para solos, segundo a mesma fonte. Os menores teores de $\mathrm{Pb}$ total foram verificados para o Ponto 7 (Quadro 4), situado na área de sepultamento de indigentes (Quadro 1). Nessas condições, devido à maior simplicidade dos sepultamentos, tem-se menor quantidade de fontes potenciais de metais pesados. Contudo, a área dos indigentes situa-se na posição mais baixa do terreno, próxima aos rios que cortam o cemitério (Figura 1d,e), com nível hidrostático a apenas 0,9 a $1,4 \mathrm{~m}$ de profundidade (Romanó, 2003), o que facilita a passagem dos poluentes para as águas subterrâneas.

Ainda considerando os limites da CETESB (2001), os teores de Cr e Ni (Quadro 4), de maneira geral, são superiores aos valores de alerta ( $\mathrm{Cr} 75 \mathrm{mg} \mathrm{kg}^{-1} \mathrm{e} \mathrm{Ni}$ $30 \mathrm{mg} \mathrm{kg}^{-1}$ ). Esses metais, normalmente, são utilizados como matéria-prima das partes metálicas dos caixões na forma de liga cromo-níquel (Silva, 1999).

Outro comportamento que indica contaminação nos solos do cemitério é a grande variação nos teores totais dos metais entre as profundidades avaliadas (Quadro 4), com maiores teores de metais nas amostras tomadas na subsuperfície (profundidade de 20 a $120 \mathrm{~cm}$ ). Caso a única fonte de metais pesados dos solos fosse o material de origem (teores naturais), esperavam-se concentrações mais próximas entre as amostras tomadas em diferentes profundidades no mesmo ponto de amostragem. Nesse aspecto, verificase uma possível contaminação pontual para $\mathrm{Cr}$ no Ponto 2, profundidade de 80 a $120 \mathrm{~cm}$; Pb no Ponto 3, profundidade de 20 a $80 \mathrm{~cm}$, Ponto 6 , profundidade de 20 a $80 \mathrm{~cm}$, e Ponto 2, profundidade de 80 a $120 \mathrm{~cm}$; e $\mathrm{Ni}$ no Ponto 7 , profundidade de 80 a $120 \mathrm{~cm}$. Na amostra 6 (ponto de coleta 2) os teores de $\mathrm{Cr}$ e $\mathrm{Pb}$ atingiram 616,3 e $260,2 \mathrm{mg} \mathrm{kg}^{-1}$, respectivamente (Quadro 4). Vale notar que o ponto de coleta 2 situavase em uma área com intensa ocupação de jazigos. $\mathrm{O}$ coeficiente de correlação entre teores totais de $\mathrm{Pb}$ e $\mathrm{Cr}$ foi alto e significativo $(r=0,9, p<0,001)$, o que pode indicar que esses metais apresentaram a mesma fonte poluidora. Comportamento semelhante foi observado por Spongberg \& Becks (2000) em cemitério de Ohio, 
Quadro 4. Teores totais e trocáveis de metais pesados nas amostras de solos do Cemitério Municipal de Santa Cândida ${ }^{(1)}$

\begin{tabular}{|c|c|c|c|c|c|c|c|c|c|c|c|c|}
\hline \multirow{2}{*}{ Amostra } & \multirow{2}{*}{$\begin{array}{c}\text { Ponto de } \\
\text { amostragem }\end{array}$} & \multirow{2}{*}{$\begin{array}{l}\text { Profundidade } \\
\text { de coleta }\end{array}$} & \multicolumn{5}{|c|}{ Teores totais } & \multicolumn{5}{|c|}{ Teores trocáveis } \\
\hline & & & $\mathrm{Cr}$ & $\mathrm{Cu}$ & $\mathbf{P b}$ & $\mathrm{Ni}$ & $\mathrm{Zn}$ & $\mathrm{Cr}$ & $\mathrm{Cu}$ & $\mathrm{Ni}$ & $\mathbf{P b}$ & Zn \\
\hline & & $\mathrm{cm}$ & \multicolumn{10}{|c|}{$-\mathrm{mg} \mathrm{kg}^{-1}$} \\
\hline 1 & $\mathrm{P} 1$ & $0-20$ & 132,5 & 54,6 & 36,6 & 35,5 & 111,8 & nd & 0,65 & nd & 9,73 & 1,20 \\
\hline 2 & & $20-80$ & 127,3 & 57,6 & 50,8 & 40,8 & 123,6 & nd & 0,56 & 0,12 & 9,06 & 1,39 \\
\hline 3 & & $80-120$ & 130,2 & 60,1 & 78,8 & 55,9 & 137,6 & nd & 0,75 & nd & 11,97 & 1,73 \\
\hline 4 & $\mathrm{P} 2$ & $0-20$ & 95,4 & 51,3 & 40,0 & 29,0 & 95,7 & nd & 0,64 & nd & 8,60 & 1,04 \\
\hline 5 & & $20-80$ & 96,5 & 67,1 & 59,8 & 33,3 & 97,1 & nd & 0,59 & nd & 7,10 & 0,65 \\
\hline 6 & & $80-120$ & 516,3 & 57,6 & 260,2 & 33,5 & 100,1 & nd & 0,43 & nd & 6,94 & 0,68 \\
\hline 7 & P3 & $0-20$ & 103,7 & 39,7 & 33,4 & 23,1 & 108,7 & nd & 0,40 & nd & 7,10 & 2,20 \\
\hline 8 & & $20-80$ & 79,2 & 27,2 & 59,2 & 20,7 & 73,9 & nd & 0,51 & nd & 6,90 & 1,54 \\
\hline 9 & & $80-120$ & 119,0 & 31,5 & 30,2 & 28,2 & 78,6 & nd & 0,42 & nd & 6,71 & 1,35 \\
\hline 10 & $\mathrm{P} 4$ & $0-20$ & 110,0 & 41,5 & 29,9 & 36,3 & 136,0 & nd & 0,59 & nd & 5,98 & 5,95 \\
\hline 11 & & $20-80$ & 157,2 & 36,7 & 29,3 & 41,4 & 128,6 & nd & 0,53 & nd & 11,20 & 1,19 \\
\hline 12 & & $80-120$ & 153,5 & 39,7 & 30,3 & 44,5 & 128,9 & nd & 0,56 & nd & 9,74 & 1,79 \\
\hline 13 & P5 & $0-20$ & 146,8 & 30,9 & 21,9 & 47,7 & 103,9 & nd & 0,52 & nd & 7,86 & 0,56 \\
\hline 14 & & $20-80$ & 89,7 & 25,8 & 22,0 & 32,1 & 89,2 & nd & 0,52 & nd & 7,84 & 1,62 \\
\hline 15 & & $80-120$ & 121,8 & 30,4 & 17,1 & 58,7 & 102,6 & nd & 0,44 & nd & 10,60 & 1,29 \\
\hline 16 & P6 & $0-20$ & 123,0 & 36,9 & 25,4 & 46,9 & 111,6 & nd & 0,54 & nd & 6,15 & 1,06 \\
\hline 17 & & $20-80$ & 116,4 & 64,2 & 58,1 & 51,9 & 133,4 & nd & 0,51 & 0,12 & 7,82 & 1,29 \\
\hline 18 & & $80-120$ & 132,9 & 59,0 & 31,0 & 56,2 & 129,5 & nd & 0,45 & nd & 7,10 & 1,23 \\
\hline 19 & $\mathrm{P} 7$ & $0-20$ & 118,0 & 35,5 & 24,9 & 40,6 & 110,6 & nd & 0,40 & nd & 7,69 & 1,23 \\
\hline 20 & & $20-80$ & 113,8 & 38,0 & 14,4 & 48,7 & 113,6 & nd & 0,59 & nd & 5,76 & 0,75 \\
\hline 21 & & $80-120$ & 148,3 & 42,8 & 17,0 & 81,4 & 110,0 & nd & 0,38 & nd & 4,67 & 1,25 \\
\hline
\end{tabular}

(1) nd: não detectado pelo método analítico (espectrometria de absorção atômica).

USA, onde os solos apresentaram maiores teores de $\mathrm{Fe}, \mathrm{Pb}, \mathrm{Cu}, \mathrm{Zn}$, Co e As na profundidade equivalente aos sepultamentos.

O teor de Cr e Ni trocáveis das amostras não pode ser detectado por espectrometria de absorção atômica (Quadro 4). A grande diferença entre os teores totais e trocáveis deve-se a formas mais estáveis dos metais, preferencialmente nas formas estruturais e adsorvidas especificamente, formando complexos de esfera interna com os grupos aluminol das bordas da caulinita e com a superfície hidroxilada dos óxidos de $\mathrm{Fe}$ e $\mathrm{Al}$ (Singh \& Gilkes, 1992; Sodré et al., 2001). Outro fator que favoreceu o baixo teor de metais pesados trocáveis foram os altos teores de cátions polivalentes nos solos, notadamente $\mathrm{Al}^{3+}$ (Quadro 1). Segundo Ross (1994) e Pierangeli (1999), o efeito da concentração total de eletrólitos pode influenciar a atividade dos metais pesados na solução do solo, pois contribuem para a lixiviação destes metais pesados pela competição entre os cátions pelos sítios de adsorção. Mesmo assim, não é comum encontrar $\mathrm{Pb}$ nas formas solúvel e trocável nos solos e sedimentos, a não ser em caso de contaminação recente, pois o $\mathrm{Pb}^{2+}$, após ser adicionado aos solos, leva em média de 24 a 48 h para ser imobilizado fortemente pelos colóides do solo (Alloway, 1990).

A relação entre causa e efeito da presença de metais pesados no solo não foi possível de ser estabelecida com base em propriedades químicas do solo (CTC total, teor de C orgânico e atividade da fração de argila) e mineralogia da fração de argila ( $\mathrm{Fe}$ e $\mathrm{Al}$ - $\mathrm{OA}, \mathrm{Fe}$ e $\mathrm{Al}$ - DCB e teores de caulinita e gibbsita), influenciados diretamente pelo material de origem, pois os valores dos coeficientes de correlação entre esses atributos foram inferiores a 0,6. Assim, é possível que a ocorrência de metais pesados em camadas específicas do solo do cemitério (Quadro 4) seja concordante com a profundidade de sepultamento e com a natureza e quantidade de metais da fonte poluidora, o que independe das características químicas e mineralógicas do solo. Os solos, no entanto, apresentaram alta capacidade adsortiva de metais por serem de textura argilosa, com CTC alta e predomínio de caulinita e ocorrência de VHE e esmectita na fração de argila, minerais com predomínio de cargas elétricas negativas. Tais características são importantes para o tamponamento do solo aos metais pesados e para diminuir o risco de contaminação do nível hidrostático e de cursos d'água.

\section{CONCLUSÕES}

1. Os solos do cemitério apresentaram grande potencial de tamponamento de metais pesados, com altos valores de CTC e atividade da fração argila e 
predomínio de caulinita e ocorrência de vermiculita com hidroxi-Al entrecamadas e esmectita na fração argila.

2. A inumação foi responsável pelo aumento nos teores de metais pesados nos solos do cemitério. Não se verificou efeito do material de origem e dos atributos químicos e mineralógicos do solo sobre o acúmulo de metais pesados, reflexo da contaminação mais intensa em apenas alguns pontos de amostragem e camadas de solo. Os maiores teores de metais pesados foram obtidos nas amostras coletadas na subsuperfície, possivelmente pela maior proximidade aos locais de sepultamento.

3. No cemitério Santa Cândida, o tipo de sepultura influenciou o potencial de poluição do solo por metais pesados, sendo o jazigo considerado o de maior risco de poluição ambiental, principalmente por $\mathrm{Cr}$ e $\mathrm{Pb}$.

\section{LITERATURA CITADA}

ALLOWAY, B.J. Heavy metals in soils. London, Blackie A \& $\mathrm{P}$, 1993. 339p.

ARCHELA, E. Faciologia e ambiente de sedimentação. São Paulo, Instituto de Geociências da Universidade de São Paulo, 1986. 132p. (Projeto de Pesquisa)

BIGARELLA, J.J. \& SALAMUNI, R. Caracteres texturais dos sedimentos da Bacia de Curitiba. B. Geol. UFPR, 7:1-164, 1962.

BOUWER, H. Groundwater hydrology. New York, McGrawHill, 1978. 375p.

CHOLOPECKA, A.; BACON, J.R.; WILSON, M.J. \& KAY, J. Forms of cadmium, lead, and zinc in contaminated soils from southwest Poland. J. Environ. Quality, 25:69-79, 1996.

COMPANHIA DE TECNOLOGIA DE SANEAMENTO AMBIENTAL - CETESB. Relatório de estabelecimento de valores orientadores para solos e águas subterrâneas no Estado de São Paulo. São Paulo, 2001.

CURCIO, G.R.; LIMA, V.C. \& GIAROLA, N.F.B. Antropossolos: Proposta de ordem (1 ${ }^{\text {a }}$ aproximação). Colombo, Embrapa Florestas, 2004. (Digital)

CURI, N. \& FRANZMEIER, D.P. Toposequence of Oxisols from the Central Plateau of Brazil. Soil Sci. Soc. Am. J., 48:341-346, 1984.

DAVIES, B.E. Lead. In: ALLOWAY, B.J., ed. Heavy metals in soils. New York, John Wiley, 1990. p.177-193.

ELLIOTT, H.A.; LIBERATI, M.R. \& HUANG, C.P. Competitive adsorption of heavy metals by soils. J. Environ. Quality, 15:214-217, 1986.

EMPRESA BRASILEIRA DE PESQUISA AGROPECUÁRIA EMBRAPA. Centro Nacional de Pesquisa de Solos. Manual de métodos de análise de solo. 2.ed. Rio de Janeiro, 1979. $212 \mathrm{p}$
EMPRESA NACIONAL DE PESQUISA AGROPECUÁRIA EMBRAPA. Centro Nacional de Pesquisa de Solos. Levantamento de reconhecimento dos solos do Estado do Paraná. Rio de Janeiro, Londrina, 1984. Tomo I. 413p.

GEE, G.W. \& BAUDER, J.W. Particle-size analysis. In: KLUTE, A., ed. Methods of soil analysis. 2.ed. Madison, American Society of Agronomy, 1986. p.383-412.

GHIDIN, A.A.; MELO, V.F.; LIMA, V.C. \& LIMA, J.M.J.C. Toposseqüências de Latossolos originados de rochas basálticas no Paraná. I-Mineralogia da fração de argila. R. Bras. Ci. Solo. 30:293-306, 2006.

JACKSON, M.L. Soil chemical analysis - advanced course. Madison, Prentice-Hall, 1979. 895p.

JONES, L.H.P.; JARVIS, S.C. \& COWLING, D.W. Lead uptake from soils by perennial ryegrass and its relation to the supply of an essential element (sulphur). Plant Soil, 38:605-619, 1973.

KÄMPF, N. \& SCHWERTMANN, U. Goethite and hematite in a climosequence in Southern Brazil and their application in classification of kaolinitic soils. Geoderma, 29:27-39, 1983.

KER, J.C.; MOTTA, P.E.F.; RESENDE, M.; CARVALHO FILHO, A. \& ARAÚJO, W.S. Elementos traços em Latossolos Roxos desenvolvidos de diferentes materiais de origem. In: CONGRESSO BRASILEIRO DE CIÊNCIA DO SOLO, 24., Goiânia, 1993. Resumos. Goiânia, Sociedade Brasileira de Ciência do Solo, 1993. p.319-320.

LIM, C.H. \& JACKSON, M.L. Dissolution for total elemental analysis. In: PAGE, A.L., ed. Methods of soil analysis. Part 2: Chemical an microbiological properties. Madison, American Society of Agronomy, 1986. p.1-12.

McBRIDE, M.B. Environmental chemistry of soils. New York, Oxford, 1994. 406p.

McKEAGUE, J.A. Manual on soil sampling and methods of analysis. Ottawa, Canadian Society of Soil Science, 1978. $212 \mathrm{p}$.

McKEAGUE, J.A. \& DAY, J.H.D. Dithionite and oxalateextractable $\mathrm{Fe}$ and $\mathrm{Al}$ as aids in differentiating various classes of soils. Can. J. Soil Sci., 46:13-22, 1966.

MEHRA, O.P. \& JACKSON, M.L. Iron oxide removal from soils and clay by a dithionite-citrate system buffered with sodium bicarbonate. Clays Clay Miner., 7:317-327, 1960.

MELO, V.F. Potássio e magnésio em minerais de solos e relação entre propriedades da caulinita com formas não trocáveis destes nutrientes. Viçosa, MG, Universidade Federal de Viçosa, 1998. 205p. (Tese de Doutorado)

MELO, V.F.; FONTES, M.P.F.; NOVAIS, R.F.; SINGH, B. \& SCHAEFER, C.E.G.R. Características dos óxidos de ferro e de alumínio de diferentes classes de solos. R. Bras. Ci. Solo, 25:19-32, 2001b.

MELO, V.F.; SINGH, B.; SCHAEFER, C.E.G.R.; NOVAIS, R.F. \& FONTES, M.P.F. Chemical and mineralogical properties of kaolinite-rich Brazilian soils. Soil Sci. Soc. Am. J, 65:1324-1333, 2001a. 
NAIDU, R.; SUMNER, M.E. \& HARTER, R.D. Sorption of heavy metals in strongly weathered soils: An overview. Environ. Geochem. Health, 20:5-9, 1998.

PACHECO, A. O problema geo-ambiental da localização de cemitérios em meio urbano. São Paulo, CEPAS, 1997. $48 \mathrm{p}$.

PACHECO, A. Os cemitérios como risco potencial para as águas subterrâneas. R. SPAM, 17:25-48, 1986.

PIERANGELI, M.A.P. Chumbo em Latossolos brasileiros: Adsorção e dessorção sob efeito de $\mathrm{pH}$ e força iônica. Lavras, Universidade Federal de Lavras, 1999. 108p. (Tese de Mestrado)

PIRES, A.C.D.; MELO, V.F.; MOTTA, A.C.V. \& LIMA, V.C. Major soil classes of the metropolitan region of Curitiba (PR), Brazil: I - Mineralogical characterization of the sand, silt and clay fractions. Braz. Arch. Biol. Technol., 50:169181, 2007a.

PIRES, A.C.D.; MELO, V.F.; MOTTA, A.C.V. \& LIMA, V.C. Major soil classes of the metropolitan region of Curitiba (PR), Brazil: II - Interaction of $\mathrm{Pb}$ with mineral and organic constituents. Braz. Arch. Biol. Technol., 50:18-192, 2007b.

ROMANÓ, E.N.L. Caracterização do meio físico no Cemitério Municipal do Boqueirão e no Cemitério Municipal de Santa Cândida no município de Curitiba - PR. Curitiba, Universidade Federal do Paraná, 2003. 98p. (Tese de Mestrado)

ROSS, S.M. Toxic metals in soil-plant systems. England, John Wiley \& Sons, 1994. 286p.

SALAMUNI, E. \& STELLFELD, M.C. Banco de dados geológicos geo-referenciados da Bacia Sedimentar de Curitiba (PR) como base de sistema de informação geográfica (SIG). B. Paranaense Geoci., 49:21-32, 2001.

SCHWERTMANN, U. \& KÄMPF, N. Properties of goethite and hematite in kaolinitic soils of Southern and Central Brazil. Soil Sci., 139:344-350, 1985.
SCHWERTMANN, U. \& TAYLOR, R.M. Iron oxides. In: DIXON, J.B. \& WEED, S.B., eds. Minerals in soil environments. 2.ed. Madison, Soil Science Society of America, 1989. p.380-427.

SILVA, M. A influência dos cemitérios no meio ambiente. (digital). In: FÓRUM SINCEPAR CEMITÉRIOS - IMPACTO AMBIENTAL, 1., Curitiba, 1999. Resumos Curitiba, SINCEPAR, 1999.

SINGH, B. \& GILKES, R.J. Properties of soil kaolinites from South-western Australia. J. Soil Sci., 43:645-667, 1992.

SODRÉ, F.F.; LENZI, E. \& COSTA, A.C.S. Utilização de modelos físico-químicos de adsorção no estudo do comportamento do cobre em solos argilosos. Química Nova, 24:324-330, 2001.

SPARKS, D.L. Environmental soil chemistry. San Diego, Academic Press, 1995. 267p.

SPONGBERG, A.L. \& BECKS, P.M. Inorganic soil contamination from cemeteries leeched. Water, Air, Soil Poll., 117:313-327, 2000.

SPOSITO, G. The chemistry of soils. New York, Oxford University Press, 1989. 277p.

SPOSITO, G. The surface chemistry of soils. New York, Oxford University Press, 1984. 234p.

TARİ, G.; BOBOS, I.; GOMES, C.S.F. \& FERREIRA, J.M.F. Modification of surface charge properties during kaolinite to halloysite- $7 \AA$ transformation. J. Colloid Interface Sci., 210:360-366, 1999

WHITTIG, L.D. \& ALLARDICE, W.R. X-ray diffraction techniques. In: KLUTE, A., ed. Methods of soil analysis. Madison, American Society of Agronomy, 1986. p.331-362.

WOWK, G.I.T. \& MELO, V.F. Avaliação do nível de chumbo, em solo de várzea, proveniente da reciclagem de bactérias. R. Bras. Eng. Agríc. Amb., 9:613-622, 2005.

ZANELLO, S. Caracterização mineralógica e avaliação dos teores de $\mathrm{Pb}, \mathrm{Cr}, \mathrm{Ni}, \mathrm{Cu}$ e $\mathrm{Zn}$ nos solos do entorno do aterro sanitário da Caximba em Curitiba (PR). Curitiba, Universidade Federal do Paraná, 2006. 78p. (Tese de Mestrado) 